\title{
Semantic and spatial factors in environmental memory
}

\author{
AMANDA A. MERRILL and JOHN C. BAIRD \\ Dartmouth College, Hanover, New Hampshire
}

\begin{abstract}
Reaction time (RT) in simple categorization tasks was predicted to vary as a function of the relatedness among environmental items. Differences in RT were interpreted as reflecting differences in proximity or strength of associations in environmental memory. In Experiment 1 , subjects sorted names of familiar local buildings according to which seemed to go together. Hierarchical cluster analysis revealed major clusters whose members were related in function and, within these, smaller clusters of buildings related by spatial proximity. In Experiment 2, subjects responded "Yes" if two items on a trial were both local buildings and "No" if one item was local and one nonlocal. Subjects responded significantly faster to pairs taken from the cluster analysis that were related by both spatial proximity and function than they did to unrelated pairs or pairs related in function only. In Experiment 3, a free-associaton task identified related pairs of spatially proximate, functionally dissimilar environmental items. In Experiment 4, RTs to these pairs did not differ from RTs to pairs of spatially proximate, functionally dissimilar items or from RTs to pairs unrelated functionally and spatially. Spatial proximity and functional similarity together contribute to the organization in memory of buildings in the physical environment.
\end{abstract}

Interest in environmental memory has concentrated on what aspects of an environment people recall and how accurate their memories are. Two approaches have prevailed. In the first, individuals sketch maps of a given environment. These maps are analyzed for content and accuracy and are compared on the basis of subject variables, such as occupation, length of residence, and customary mode of transportation (see reviews by Baird, Merrill, \& Tannenbaum, 1979; Evans, 1980; Magaña, Evans, \& Romney, 1981).

In the second approach, subjects give numerical estimates of the relative distances between pairs of recalled items, and psychophysical functions describe the relationship between perceived and actual distances (see reviews by Baird, Wagner, \& Noma, 1982; Gärling, Böök, \& Lindberg, 1985). In addition, two-dimensional maps are generated from these unidimensional distance estimates by various scaling techniques (Baird et al., 1979; Baird et al., 1982; Golledge, Rivizzigno, \& Spector, 1976; Golledge \& Zannaras, 1973; MacKay, 1976; Magaña et al., 1981). Comparisons of these maps to the actual positions of items show that, with some exceptions, memory for spatial relations is fairly accurate (for an exception, see Stevens \& Coupe, 1978).

What has not been studied extensively is how information about the natural, everyday environment is coded and organized in memory and how this relates to the coding and organization of other kinds of information. A physi-

\footnotetext{
This research is a portion of the senior author's doctoral dissertation completed at Dartmouth College. We thank Gail McKoon and Roger Ratcliff for their expert advice and encouragement on all phases of this research. We also appreciate the constructive comments of Roberta Klatzky and two anonymous reviewers. Reprint requests should be sent to John C. Baird, Department of Psychology, Dartmouth College, Hanover, NH 03755.
}

cal environment can be considered an array of both semantic and analog information-a collection of meaningful items arranged in a continuous space. It seems appropriate to integrate the study of environmental memory with research on semantic and spatial memory.

Numerous experiments have been conducted within the framework of semantic memory viewed as a system of hierarchical categories and exemplars (Collins \& Loftus, 1975; Collins \& Quillian, 1969; Glass \& Holyoak, 1975; Meyer, 1970). The critical result is one of semantic priming: Reaction time (RT) in lexical decision tasks is shortened significantly if the target word is a frequent freeassociate of the preceding word (McKoon \& Ratcliff, 1976; Meyer \& Schvaneveldt, 1972; Neely, 1976, 1977; Posner \& Snyder, 1975).

Herrmann, Shoben, Klun, and Smith (1975) found that distance between semantic categories in a cluster configuration (dendrogram) was an accurate predictor of RT in a subsequent task in which subjects decided if two words were members of the same category. If two words were from different, but clustered, categories, subjects responded significantly more slowly than they did to words from more disparate categories; in this case, semantic relatedness interfered with their making the correct (negative) response.

More recently, Hirtle and Jonides (1985) developed an original method for revealing the hierarchical groupings of environmental buildings and landmarks. By noting a subject's recall order of items, the analysis produced ordered trees to represent the subject's conception (assumed organization in memory) of his or her familiar environment. Subsequent tests involving distance estimation and map sketching suggested that cluster boundaries secured by the recall procedure were psychologically meaningful. 
The environinent is, of course, not simply a collection of discrete items with various meanings attached, but a specific spatial arrangement of those items. The same group of buildings shuffled about into new locations would be a different environment. Relevant to this issue are the theoretical constructs of analog representation and processing (Kosslyn, Murphy, Bemesderfer, \& Feinstein, 1977; Shepard \& Chipman, 1970). According to these authors, the memory representations of spatial relations are analogous to the representations resulting from direct perception.

This issue was addressed by Baum and Jonides (1979), who studied the mental comparison of environmental distances. Their subjects judged which of two distances in a familiar environment was shorter. It was shown that the more similar the two distances, the slower the RT. In addition, Jonides and Baum (1978) found that RT in estimating distances on a campus was a linear function of the magnitude of the distance estimates themselves. This same relationship between distance and RT has been demonstrated using a memorized map of a fictitious island (Jolicoeur \& Kosslyn, 1985; Kosslyn, Ball, \& Reiser, 1978). Such data are seen as evidence for an analog memory of spatial information differing from the propositional representation of semantic information (Cooper \& Shepard, 1978; Kosslyn, 1980; Paivio, 1976).

More recent experiments have suggested, however, that the relatedness of spatially distributed items depends on both physical distance and on nonspatial factors, such as whether items fall along the same or different travel routes independent of physical distance (McNamara, Ratcliff, \& McKoon, 1984) or whether items are located in the same or different superordinate regions of space (McNamara, 1986).

In general, memory for spatial relations has been investigated as an isolated factor, whereas research on semantic memory has concentrated on memory for categories and examples of concepts. McNamara's (1986) research combined these two areas by using artificial environments that first had to be learned by the subject. As he pointed out, it is of interest to know whether semantic factors are also important in the memory organization of the natural environment. The present research addressed this question by exploring the role of spatial relations and semantic factors in the organization of memory for a college campus and adjacent town.

\section{EXPERIMENT 1}

In Experiment 1 , the perceived relatedness among buildings in the local environment was assessed by a sorting task (as in Herrmann et al., 1975). The intention was to determine which aspects of the buildings and environment seemed most relevant to subjects' judgments of relatedness. These data, in turn, served as the basis for predictions in a timed categorization task (Experiment 2).

\section{Method}

Subjects. Forty-five Dartmouth undergraduates participated (32 males and 13 females). Twenty-eight received extra credit in an introductory psychology course; 17 were volunteers from other courses. No freshmen participated.

Materials. The name of a building on the Dartmouth campus or in the adjacent commercial district of Hanover, New Hampshire, was printed on each of 100 index cards. These included names of almost all of the dormitories, athletic facilities, classrooms, administration buildings, and restaurants, of about half of the fraternities, and of a third of the stores. The cards were arranged on a table in seven columns of 13 to 15 cards each. The location of the cards in the display varied randomly from subject to subject.

Procedure. Individuals were shown the cards and were told that the names referred to local places. They were instructed to sort the cards into piles according to "what seems to go together," and to use as few or as many piles of whatever size seemed appropriate. Cards could be isolated as one-time "piles." Subjects were instructed to set aside cards showing unfamiliar names.

\section{Results}

Individual differences. The number of piles varied from 9 to 35. Subjects who produced large numbers of piles showed evidence of attending more to the spatial proximity of buildings than did subjects who made relatively few piles. Members of the latter group invariably sorted according to the functions of the buildings: They placed all dormitories together, all fraternities together, and so forth. The subjects who produced a larger number of piles appeared to employ two strategies. Some maintained functional integrity within groupings, whereas others used a more inclusive spatial criterion.

Subjects were familiar with almost all the buildings; the two building names that were unfamiliar to many subjects were eliminated from the analysis.

Aggregate results. A hierarchical cluster analysis (maximum method, Johnson, 1967) produced an overall picture of the groupings. The raw data were the number of times each pair of place names was sorted together. Hence, the input to the cluster analysis was the lower half of a $98 \times 98$ matrix, the cell entries of which varied from 0 to 45 . Figure 1 is the resulting dendrogram.

Two factors are prominent in the organization displayed in Figure 1. First, there are several major clusters, whose members are functionally related. There are a number of well-defined clusters, including dormitories, fraternities, and classrooms. Within most of the major clusters are smaller clusters representing buildings that are not only related in function but are also located near one another. Finally, there are a few other names wedged between clusters; these are buildings that have unique functions and therefore do not fit neatly into any category.

\section{Discussion}

The primary variables that emerged from the sorting task were functional similarity and spatial proximity. The fact that function-related sorting was more prevalent than spatial-related sorting may be evidence that subjects were 


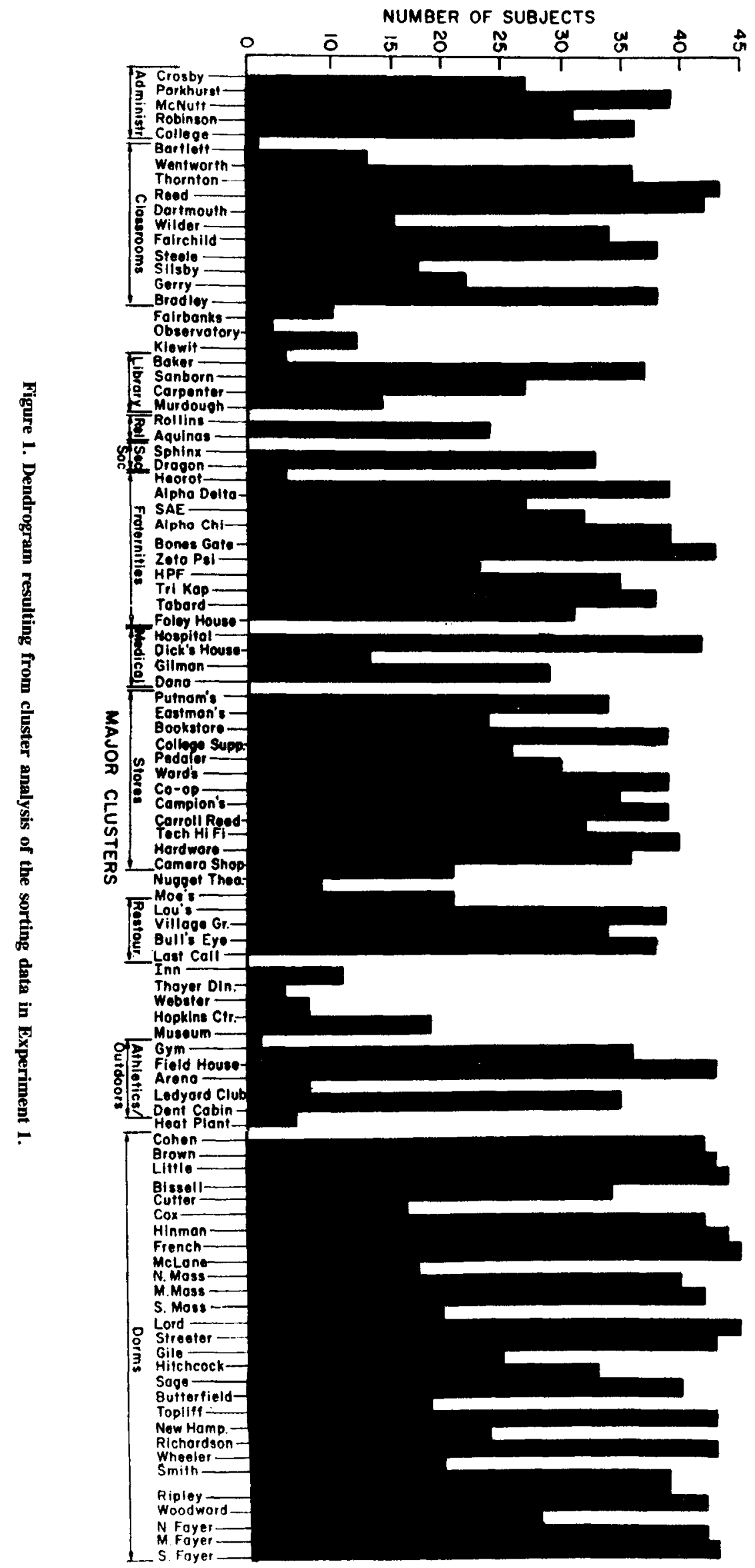


consulting a memory representation that was organized in functional (propositional) groups, or clusters, rather than along continuous spatial (analog) dimensions.

\section{EXPERIMENT 2}

Subjects were asked to indicate if two building names were both local or one was local and one nonlocal. The major prediction was that RT would vary as a function of the relatedness of the pairs of local building names. Relatedness is defined by the locations of buildings in the dendrogram resulting from Experiment 1. More specifically, there are three levels of relatedness corresponding to (1) membership in the same small cluster, representing spatial proximity and functional similarity (spatial-andfunctional), (2) membership in the same major, functional cluster, but different small clusters (function-only), and (3) membership in different major clusters (unrelated).

For the present argument, activation of a building name was assumed to prime related items in memory. If the building name was followed by one of those related items, RT to the pair would be predicted to be shortened by the priming process. It was predicted that spatial-andfunctional pairs would prime one another and, therefore, would be responded to very quickly. The unrelated pairs were predicted to yield significantly slower RTs. It was harder to predict RTs for the functional-only pairs. Those were expected to reveal something about the relative salience of spatial proximity and functional similarity in the underlying memory representation. If RTs to the functional-only pairs did not differ from RTs to spatialand-functional pairs (but did differ from RTs to unrelated pairs), this could be taken as evidence that functional similarity is the crucial factor. If they fell between spatialand-functional RTs and unrelated RTs, then an additive priming effect might be operating. Finally, if functionalonly RTs turned out to be in the same range as those for unrelated pairs, a stronger role for spatial proximity would be suggested.

\section{Method}

Subjects. Eighteen Dartmouth undergraduates participated. All were introductory psychology students who received extra course credit. Seven were freshmen, and 11 were upperclassmen; there were 8 males and 10 females.

Apparatus. Testing was conducted at a Datamedia CRT (Elite 1520) on-line with the Dartmouth Time-Sharing System (DTSS). A response latency recorder was also connected to DTSS. A black plastic template covered the terminal keyboard. Two Lucite response buttons were inserted through holes in the template, directly over two terminal keys. "Yes" and "No" labels were taped to the template, just above the buttons. The display screen was covered with black cardboard; there was a horizontal slit near the top of the cardboard, through which one line of uppercase letters could be seen.

Materials and Design. Two categories of stimuli were used. The local stimuli were names of Dartmouth buildings and commercial establishments in Hanover, New Hampshire. The other items were proper names of fictitious restaurants and stores. In choosing the latter stimuli, names that sounded or looked like actual local place names were avoided. Each subject was tested with 60 pairs of lo- cal names and 60 pairs consisting of one local and one nonlocal name (the first name always was local).

Certain pairs of local names were designated as critical pairs that would enter into the test for priming effects. Pairs were taken from the dendrogram in Experiment 1 and fell into three categories: spatial-and-functional, functional-only, and unrelated.

There were 18 target items, each paired with 3 other items to produce a spatial-and-functional pair, a functional-only pair, and an unrelated pair. An example of such a trial is the following: French-McLane (two dormitories located next door to each other), Ripley-McLane (Ripley is a dormitory across campus from McLane), and Steele-McLane (Steele is a classroom building across campus from McLane). The three items were equated as nearly as possible for number of letters. The target item was always the second member of the pair. Of the 18 target items, there were six dormitories, three fraternities, three classroom buildings, two administration buildings, the main library, the hockey arena, the hospital, and a store. None of the items used in critical pairs were members of other pairs.

Target items were crossed with subjects and relatedness in a Latinsquare design. Each subject saw all types of pairs, but saw a given target item only once. There were three lists of pairs (Lists A, B, and $C$ ), each containing 18 critical pairs ( 6 of each category). The noncritical pairs were identical across lists. Six subjects were assigned to each list.

Procedure. Subjects were tested individually. Each received 20 practice trials, followed by four blocks of 30 trials each. The mean RT on practice trials was checked immediately, and assignment to one of the three groups was made on the basis of that mean. That is, as nearly as possible, "slow" and "fast" subjects were distributed across the three groups.

Each subject received a different random order of test trials. The format of each trial was as follows: (1) A fixation cross ("+") appeared on the screen and remained for $500 \mathrm{msec}$, warning the subject that the trial was beginning and reminding him or her to look at the screen. (2) The cross disappeared and a name appeared for $250 \mathrm{msec}$. (3) After a pause of $100 \mathrm{msec}$, the name was replaced by a second name until the subject responded by hitting the "Yes" button if the two names were both local or the "No" button if one name was local and one nonlocal. The first letter of each name always appeared in the same location as the fixation cross. For half the subjects, the "Yes" button was on the left and the "No" button on the right; the positions were reversed for the other half.

Subjects were instructed to respond as quickly as possible without being reckless. When an error occurred, a brief tone of comfortable intensity was sounded before the onset of the next trial.

\section{Results}

The overall error rate was 3\%. There was no relationship between class (freshmen vs. upperclassmen) and number of errors. Three percent of the trials were discarded because RT exceeded a 2,500-msec cutoff.

Table 1 summarizes the means and standard deviations of RTs for correct responses. RTs were faster on "Yes" trials than on "No" trials, mirroring the results of Meyer and Schvaneveldt (1971) from their lexical decision task.

Table 1

Reaction Times (RT, in Milliseconds) in Experiment $2(N=18)$

\begin{tabular}{lcc}
\hline Type of Pair & Mean RT & SD \\
\hline Yes-Spatial-and-Functional & 757 & 192 \\
Yes-Functional-Only & 887 & 231 \\
Yes-Unrelated & 950 & 178 \\
Yes-Noncritical & 876 & 226 \\
No & 1105 & 334 \\
\hline
\end{tabular}


Three analyses of variance (ANOVAs) were performed on the RTs for critical "Yes" trials. In the first, subjects was treated as a random variable, and the data for the analysis were each subject's mean RT on spatial-andfunctional trials, on functional-only trials, and on unrelated trials. RT differed as a function of trial type $[F(2,34)=7.78, p<.01]$. Scheffé tests revealed that the mean RT for spatial-and-functional trials was significantly lower than both the unrelated mean $(p<.01)$ and the functional-only mean $(p<.05)$; the functional-only and unrelated means did not differ significantly.

For the second ANOVA, in which items was treated as a random variable, data were the mean RTs for each critical trial. This analysis also showed trial type to have a significant effect $[F(2,34)=11.06, p<.01]$. Once again, mean RT for spatial-and-functional trials was significantly lower than that for unrelated trials $(p<.001)$ and that for functional-only trials $(p<.05)$. Functionalonly and unrelated means were not different. Finally, a minimum quasi- $F$ (Clark, 1973) was calculated and found to be significant $(\min F=4.57, p<.05)$. This test takes both random variables into consideration simultaneously.

\section{Discussion}

A clear-cut priming effect was found. Pairs of names of places that were alike in function and also located near one another were responded to faster than were pairs that were alike in function but not spatially proximate, and faster than pairs that were not related functionally or spatially. Functional similarity alone did not have a significant effect on RTs, despite the fact that the mean RT was less than that for unrelated pairs-variability was also highest in the functional-only case (Table 1).

The obvious next question was whether or not spatial proximity between items would, by itself, produce priming. This called for pairs of places that were located near one another but that were unrelated in function. In Experiment 3, a measure of relatedness was applied that permitted a more confident choice of "spatial-only" pairs for a subsequent priming study (Experiment 4).

\section{EXPERIMENT 3}

Free association involves minimal effort by subjects, and previous studies have demonstrated priming effects with pairs of free-associates (see McKoon \& Ratcliff, 1976; Meyer \& Schvaneveldt, 1971).

\footnotetext{
Method

Subjects. There were 45 subjects ( 27 males and 18 females); 15 were freshmen, and 30 were upperclassmen. Forty-two subjects received extra credit in an introductory psychology course for their participation; 3 were volunteers from other psychology courses.

Materials. Test packets consisted of an instruction sheet and four pages of place names with spaces next to each for three responses. The place names included the 98 items from the cluster dendrogram and 21 new names consisting of four fraternities, two stores, two restaurants, two dormitories, a senior society, the central green, and nine superordinate names, such as Fraternity Row, and Dart-
}

mouth Medical School. The stimulus list was constructed so that likely associates did not closely follow one another. Half the subjects saw one list, and the other half were tested with the reverse order of items.

Procedure. One group of 13 subjects was tested in a single session, 8 subjects were tested in two groups of 4 each, and the rest participated individually. The instructions read, in part:

On the following four pages are listed names of places around Dartmouth and Hanover (buildings, geographic areas). Next to each test name write down the first other place name that comes to mind; that is, the name of the building or area that you are first reminded of. If the test name brings to mind more than one place name, write the names in the order in which you think of them, working from left to right across the answer sheet (up to three names).

If you don't recognize an item at all and/or the item doesn't bring to mind any other place names, leave it blank. You may respond with a given name more than once.

\section{Results}

Subjects skipped few items, and almost all subjects gave more than one response to a sizable proportion of the stimuli (on the average, $30 \%-50 \%$ of the names). The results are considered from two perspectives: (1) comparison with the results of Experiment 1 (the sorting task) and (2) the most frequent types of responses.

Comparison with the results of Experiment 1. For each stimulus name, first, second, and third responses were tabulated, and the most frequent response was calculated (adding across all three answer positions).

A check was made to see if items that were frequently sorted together in Experiment 1 were also likely to be given as free-associates to one another. This involved 61 building names that had been members of small clusters (defined as groups of items sorted together by at least 35 of the 45 subjects). Two additional clusters of three dormitories each had been relabeled with their common superordinate names for the free-association task and thus were not included. If a small cluster member was most frequently responded to with another cluster member, a "Yes" was tallied. For example, the dormitories New Hampshire Hall and Topliff Hall formed a small cluster and were also the most frequently given free-associates to one another. On the other hand, Kiewit Computation Center was the most frequent response to TriKap fraternity, but these two names had not been clustered together. This was counted as a "No." If a stimulus item was responded to most frequently with a name not included in Experiment 1, that was tallied as "Not available." The totals were: "Yes" $=43$, "No" $=10$, and "Not available" $=8$.

Summary of most frequent responses. Although the instructions did not specifically call for the use of local place names as responses, almost all responses were local names.

Almost half (55 of 113) of the most frequent responses were related to the stimulus words both functionally and spatially, and these cases represented the only symmetrical associations (item $A$ yields $B$ and item $B$ yields $A$ ). Such pairs were not used in the subsequent priming task (Experiment 4). There were a considerable number of 
responses related to the stimulus by spatial proximity only (28). The number of "function-only" responses was much smaller (7), and in 5 of the 7 cases, names of restaurants or stores were responded to with restaurant and store names, respectively-not the nearest establishments, but places that were located along the same main street.

These findings can be summarized as follows: For a given building or location, if there was a functionally related building or location nearby, then that was the most frequently cited associate; otherwise, the stimulus was most frequently responded to with a functionally unrelated but spatially proximate building or location. If, in the latter case, there were several possibilities for close associates (i.e., several roughly equidistant items), the relative prominence of buildings was influential.

\section{Discussion}

The free-association procedure provided data for comparison with the associations gleaned from the sorting task of Experiment 1 and did in fact uncover associations between spatially proximate, functionally dissimilar stimuli that were not evident in the cluster dendrogram. Experiment 4 determined whether or not these spatial-only associations were strong enough to elicit a priming effect.

\section{EXPERIMENT 4}

In Experiment 2, a priming effect was demonstrated for pairs of buildings that were spatially proximate and functionally similar, the pairs that, according to the sorting experiment, were most closely related. In Experiment 4, the selection of pairs was based on the free-association results of Experiment 3. A priming effect was expected to be evident for items that were closely associated. If spatial proximity was the critical factor organizing all stimuli in environmental memory, priming would also be expected to be found with a second group of pairs termed "arbitrary" pairs. These were pairs of spatially proximate (and functionally dissimilar) items that were seldom or never given as free-association responses to one another.

\section{Method}

Subjects. Twenty-one Dartmouth undergraduates participated (14 males and 7 females); 7 were freshmen, and 14 were upperclassmen. Eight were introductory psychology students who received extra course credit for there participation; 13 were recruited from other psychology courses.

Apparatus. The apparatus was identical to that used in Experiment 2.

Materials and Design. There were three lists. Each consisted of 60 pairs of local names and 60 pairs of one local and one nonlocal name. Seven subjects were assigned to each list. Among the pairs of local names in each list were 15 critical pairs. Each critical pair consisted of a target item preceded by one of three items; the three were equated as nearly as possible for number of letters. Each list included 5 critical pairs from each of three categories. The first category consisted of pairs of names of spatially proximate, functionally unrelated places that the free-association proce- dure had shown to be related (free-association pairs). An example is the pair Dartmouth Hall-Fayerweather. Dartmouth Hall is a classroom located directly in front of the Fayerweather dormitory. In the environment under consideration, there are fewer spatial-only building pairs for potential association than there are spatial-andfunctional pairs. Because of the layout of the campus, almost every building is situated next to at least one other building of the same or similar function (e.g., most dormitories are clustered). The pairs chosen were the 15 strongest examples of spatial-only association. The mean number of subjects (of 45) associating each pair was $14(S D=5.06)$. This refers to unidirectional association (i.e., how many times Fayerweather was given as a response to Dartmouth Hall). All the pairs used were asymmetrical in that if $B$ was the most frequent response to $A$, it was not true that $A$ was the most frequent response to $B$.

The second category (arbitrary) consisted of pairs of spatially proximate, functionally different items, chosen by the experimenters, that were not shown to be related in the free-association study (e.g., Thornton Hall-Fayerweather; Thornton is another classroom building located in front of Fayerweather, next to Dartmouth Hall). Finally, there were critical pairs of items not related functionally or spatially and not given as free-associates to one another (labeled "unrelated"). Robinson Hall-Fayerweather was one; Robinson Hall is an administration building across the central green from Fayerweather.

The noncritical pairs were based on those from Experiment 2, with substitutions made so that names used in critical pairs did not appear in noncritical pairs. Also, three new noncritical pairs of local names were added. Noncritical pairs were the same for all three lists.

Procudure. The procedure was identical to that used in Experiment 2.

\section{Results}

The overall error rate was $3 \%$. Freshmen and upperclassmen did not differ in number of errors. Two percent of the trials were discarded because RT exceeded a 2,500-msec cutoff.

Table 2 summarizes the RTs for correct responses. As expected, RTs were slower on "No" trials than on "Yes" trials. The difference between RTs on critical trials as a whole and on the other "Yes"' trials was somewhat surprising. One factor that may have contributed to this outcome is that, overall, critical pairs took longer to read: Forty-seven percent of the critical trials consisted of two multiword local names, whereas the comparable figure for noncritical trials was $18 \%$.

Inspection of the mean RTs and their associated standard deviations foretells the results of the ANOVAs: Relatedness did not have a significant effect. In the first ANOVA, treating subjects as the random variable, $F(2,40)=.51(p>.05)$; in the second, in which items was the random variable, $F(2,28)=.15(p>.05)$.

Table 2

Reaction Times (RTs, in Milliseconds) in Experiment $4(N=21)$

\begin{tabular}{lcc}
\hline Type of Pair & Mean RT & SD \\
\hline Yes-Free-Association & 817 & 336 \\
Yes-Arbitrary & 861 & 316 \\
Yes-Unrelated & 844 & 344 \\
Yes-Noncritical & 753 & 272 \\
No & 902 & 304 \\
\hline
\end{tabular}




\section{Discussion}

A priming effect was not found with pairs of spatially proximate, functionally dissimilar buildings-even those that the free-association results had suggested were related in subjects' internal representations of the environment. However, the mean RT for this condition was smaller than that for either the arbitrary or the unrelated case.

Obviously, people can recall information about spatial proximity. Given a building name, they can form an image of the building and the area surrounding it, and can estimate and compare distances (Baum \& Jonides, 1979; Jonides \& Baum, 1978). However, the results of Experiment 4 , in conjunction with those of the sorting task, indicate that these spatial relations do not by themselves govern the organization of environmental memory.

\section{GENERAL DISCUSSION}

The environment seems to be an ideal source for studying the coding of spatial and semantic information in combination. Spatial relationships are an integral part of an environment; this differentiates environments from other collections of concepts stored in memory (e.g., books, college classmates). However, the absence of priming effects in Experiment 4 suggests that spatial relations do not play a unique role in environmental memory.

Spatial proximity is probably one of many factors that contribute to an overall level of relatedness among environmental items. The results from Experiment 2 indicate that one formula for high relatedness is the combination of spatial proximity and functional similarity. A simple model might help explain the results from Experiments 2 and 4 by assuming: (1) Both functional and spatial relatedness by themselves lead to weak priming. (2) Under the present circumstances, neither factor alone is powerful enough to yield significant priming. (3) When both factors are present, however, their combined effectiveness is an additive function of the two components and thus yields a significant priming effect for functionalspatial pairs. This model is also consistent with the clustering and free-association data (Experiments 1 and 3), which indicate a coupling in memory between buildings that are both spatially and functionally related. Future tests of such a model might include several measures of spatial relatedness-for example, estimated walking time between buildings, observed frequencies of people moving from one building to another, and judged similarity of building function.

\section{REFERENCES}

Baird, J. C., Merrel, A. A., a Tannenbaum, J. (1979). Cognitive representation of spatial relations: II. A familiar environment. Journal of Experimental Psychology: General, 108, 92-98.

BAIRD, J. C., WAGNER, M., Noma, E. (1982). Impossible cognitive spaces. Grographical Analysis, 14, 204-216.

Baum, D. R., Jonides, J. (1979). Cognitive maps: Analysis of comparative judgments of distance. Memory \& Cognition, 7, 462-468.
Clark, H. H. (1973). The language-as-fixed-effect fallacy: A critique of language statistics in psychological research. Journal of Verbal Learning \& Verbal Behavior, 12, 335-359.

Collins, A. M., Loftus, E. F. (1975). A spreading-activation theory of semantic processing. Psychological Review, 82, 407-428.

Collins, A. M., \&uillian, M. R. (1969). Retrieval time for semantic memory. Joumal of Verbal Learning \& Verbal Behavior, 8 , 240-248.

COOPER, L. A., \& ShEPARD, R. N. (1978). Transformations on representations of objects in space. In E. C. Carterette \& M. Friedman (Eds.), Handbook of perception: Space and object perception (Vol. 8). New York: Academic Press.

Evans, G. W. (1980). Environmental cognition. Psychological Bulletin, 88, 259-287.

GÄrLING, T., Böök, A., \& LiNdeERG, E. (1985). Adults' memory representations of the spatial properties of their everyday physical environment. In $\mathrm{A}$. Cohen (Ed.), The development of spatial cognition. Hillsdale, NJ: Erlbaum.

Glass, A. L., \& Holyoak, K. F. (1975). Alternative conceptions of semantic memory. Cognition, 3, 313-339.

Golledge, R. G., Rivizzigno,V. L., \& SPECtor, A. (1976). Leaming about a city: Analysis by MDS. In R. G. Golledge \& G. Rushton (Eds.), Spatial choice and spatial behavior. Columbus: Ohio State University Press.

Golledge, R. G., \& ZanNaras, G. (1973). Cognitive approaches to the analysis of human spatial behavior. In W. H. Ittelson (Ed.), Environment and cognition. New York: Seminar Press.

Herrmann, D. J., Shoben, E. J., KLun, J. R., \& SmTth, E. E. (1975). Cross-category structure in semantic memory. Memory \& Cognition, 3, 591-594

HiRTLE, S. C., Jonides, J. (1985). Evidence of hierarchies in cognitive maps. Memory \& Cognition, 13, 208-217.

Johnson, S. (1967). Hierarchical clustering schemes. Psychometrika, 32, 241-254.

JoLICOEUR, P., \& KossLYN, S. M. (1985). Is time to scan visual images due to demand characteristics? Memory \& Cognition, 13, 320-332.

Jonides, J., \& BAUM, D. R. (1978, May). Cognitive maps: Analysis of distance estimases. Paper presented at the meeting of the Midwestern Psychological Association, Chicago, IL

Kosslyn, S. M. (1980). Image and mind. Cambridge, MA: Harvard University Press.

Kosslyn, S. M., Ball, T. M., \&eiser, B. J. (1978). Visual images preserve metric spatial information: Evidence from studies of visual scanning. Joumal of Experimental Psychology: Human Perception \& Performance, 4, 47-60.

Kosslyn, S. M., Murphy, G. L., Bemesderfer, M. E., \& Feinstein, K. J. (1977). Category and continuum in mental comparisons. Journal of Experimental Psychology: General, 106, 341-375.

MACKAY, D. B. (1976). The effect of spatial stimuli on the estimation of cognitive maps. Geographical Analysis, 8, 439-452.

Magaña, J. R., Evans, G. W., \& RomNEY, A. K. (1981). Scaling techniques in the analysis of environmental cognition data. Professional Geographer, 33, 294-301.

MCKOON, G. A., \& RATCLfF, R. (1976, November). Priming in episodes and semantic memory. Paper presented at the meeting of the Psychonomic Society, St. Louis, MO.

MCNamara, T. P. (1986). Mental representations of spatial relations. Cognitive Psychology, 18, 87-121.

McNamara, T. P., RATCLIF, R., McKoon, G. (1984). The mental representation of knowledge acquired from maps. Jourmal of Experimental Psychology: Learning, Memory, \& Cognition, 10, 723-732.

MEYeR, D. E. (1970). On the representation and retrieval of stored semantic information. Cognitive Psychology, 1, 242-299.

Meyer, D. E. \& SchVANeVeldT, R. W. (1971). Facilitation in recognizing pairs of words. Journal of Experimental Psychology, 90, 227-234.

NeEly, J. H. (1976). Semantic priming and retrieval from lexical memory: Evidence for facilitatory and inhibitory processes. Memory \& Cognition, 4, 648-654. 
NeELY, J. H. (1977). Semantic priming and retrieval from lexical memory: Roles of inhibitionless spreading and limited-capacity attention. Journal of Experimental Psychology: General, 106, 226-254.

PaIvio, A. (1976). Images, proposition, and knowledge. In J. M. Nicholas (Ed.), Images, perception, and knowledge. Dordrecht, The Netherlands: Reidel.

Posner, M. I. \& SNyder, C. R. R. (1975). Facilitation and inhibition in the processing of signals. In P. M. A. Rabbitt \& S. Dornic (Eds.), Attention and performance $V$. New York: Academic Press.
Shepard, R. N., Chipman, S. (1970). Second-order isomorphism of internal representations: Shapes of states. Cognitive Psychology, 1, 1-17.

Stevens, A., \& Coupe, P. (1978). Distortions in judged spatial relations. Cognitive Psychology, 10, 422-437.

(Manuscript received March 3, 1986;

revision accepted for publication August 13, 1986.) 